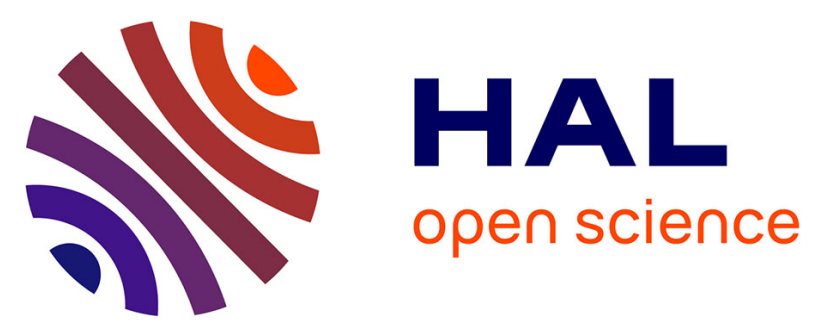

\title{
Comparison of Pleiades and LiDAR Digital Elevation Models for Terraces Detection in Farmlands
}

Giulia Sofia, Jean-Stéphane Bailly, Nesrine Chehata, Paolo Tarolli, Florent Levavasseur

\section{- To cite this version:}

Giulia Sofia, Jean-Stéphane Bailly, Nesrine Chehata, Paolo Tarolli, Florent Levavasseur. Comparison of Pleiades and LiDAR Digital Elevation Models for Terraces Detection in Farmlands. IEEE Journal of Selected Topics in Applied Earth Observations and Remote Sensing, 2016, 9 (4), pp.1567-1576. 10.1109/jstars.2016.2516900 . hal-01344541

\section{HAL Id: hal-01344541 \\ https://hal.science/hal-01344541}

Submitted on 19 Jul 2016

HAL is a multi-disciplinary open access archive for the deposit and dissemination of scientific research documents, whether they are published or not. The documents may come from teaching and research institutions in France or abroad, or from public or private research centers.
L'archive ouverte pluridisciplinaire HAL, est destinée au dépôt et à la diffusion de documents scientifiques de niveau recherche, publiés ou non, émanant des établissements d'enseignement et de recherche français ou étrangers, des laboratoires publics ou privés. 


\title{
Comparison of Pleiades and LiDAR Digital Elevation Models for terraces detection in farmlands
}

\author{
Giulia Sofia*, Jean-Stéphane Bailly ${ }^{\dagger}$, Nesrine Chehata ${ }^{\ddagger}$, Paolo Tarolli*, Florent Levavasseur ${ }^{\S}$ \\ ${ }^{*}$ University of Padova, Department Land, Environment, Agriculture and Forestry, I-35020 Legnaro \\ ${ }^{\dagger}$ AgroParisTech, UMR LISAH, F-34060 Montpellier \\ ${ }^{\ddagger}$ Bordeaux INP, EA 4592, F-33607 Pessac \\ $\S$ Inra, UMR LISAH, F-34060 Montpellier
}

\begin{abstract}
Among the most evident anthropogenic modifications of the lanscape, terraces related to agricultural activities are ubiquitous structures that constitute important investments worldwide, and they recently acquired a new relevance to modern concerns about land use management and erosion control. Conservation agriculture and terraces management are an application with great potentialities for Satellite Earth observation and the derived high resolution topography. Due to its high agility, the Pleiades satellite constellation provides new, highresolution Digital Elevation Models (DEMs) with a sub-metric resolution that could be potentially useful for this task, and their application in a farmland context is nowadays an open research line. This work provides a first analysis, performing an automatic terrace mapping from DEMs obtained from Pleiades images, as compared to LiDAR DEMs. Two existing methods are considered, the Fast Line Segment Detector (LSD) algorithm, and a geomorphometric method based on surface curvature. Despite the lower performances of Pleiades DEMs respect to the LiDAR models, the results indicate that the Pleiades models can be used to automatically detect terrace slopes greater than $2 \mathrm{~m}$ with a detection rate of more than $80 \%$ of the total length of the terraces. In addition, the results showed that when using noisy digital elevation models, the geomorphometric method is more robust, and it slightly outperforms the LSD algorithm. These results provide a first analysis on how effective Pleiades DEMs can be as an alternative to LiDAR DEMs, also highlighting the future challenges for monitoring large extents in a farmland context.
\end{abstract}

Index Terms-Stereo-photogrammetry, cultivated landscapes, LiDAR, line detection, accuracy

\section{INTRODUCTION}

In the past few decades environmental research has become aware of the extent of the human impact on ecologic and geomorphic systems [1]-[5].

Among the most evident human-induced landscape modifications, terraces related to agricultural activities are ubiquitous features, and they constitute important capital investments in a range of landscapes worldwide [4], typically enduring over many human generations [6]. The importance of terraced landscapes has been underlined from different point of views, ranging from cultural and environmental (e.g. the World Cultural Heritage Sites by UNESCO and [7]), to sustainable land use [6], [8], [9], ecosystem importance [10], [11], erosion control, runoff and water management [4], [12], [13], [19],
[21]. In recent times, terraced areas acquired a new relevance to modern concerns about land use management and erosion control [15]-[18], being the agricultural land mostly threatened by abandonment [4], or, on the other hand, intensification and specialization of agriculture resulting in heavy land levelling and/or construction of more landslide-prone bench terraces [14]. Giving the terraces obvious relevance public authorities, land managers, and researchers have called for the development of cost-effective and flexible methods for the identification and monitoring of these features [20], as a basis for a correct monitoring, and to diagnose erosion and hydrological risks at the catchment or hillslope scale [4]. Despite their importance, only few terraces have been delineated and are available in national geographical databases [4], [22]. Thus, most of the recent literature dealing with terraces approached to their identification through field survey, interviews with the local population, or interpretation of aerial photographs and successive digitalization (e.g. [6], [23], [24]). Currently, only few automatic methods have been presented to map agricultural terraces [4], [20], [25], [26].

Pleiades is the most recent satellite mission providing optical images at any point of the Earth surface [27]. Due to the agility of the sensor, the Pleiades constellation allows the acquisition of stereo pairs and triplets for highly coherent conditions [28], [29]. The agility of the satellite, and the availability of this dataset have risen questions about what is feasible, and what is efficient, regarding 3D mapping from multi-angle images sequences [27]. While the effectiveness of high resolution datasets in anthropogenic environments has already been proven (see [30] for a full review), the feasibility of Pleiades datasets in the form of Digital Surface Models (DSMs) has been proven for building extractions e.g. [27], but no work in literature has proven so far the effectiveness of Pleiades DEM for agricultural landscapes. Precision farming and agricultural control are application with great potentialities for Earth observation if efficient methodologies could be used to extract useful and accurate end users information [31], and the use of Pleiades DEMs as an alternative to LiDAR DEMs for monitoring large extents and surface changes has yet to be proven and operationally implemented.

Three questions are still unanswered: i) Are Pleiades derived 
DEMs accurate and detailed enough for mapping farmland terraces? ii) Given the same resolution, are the mapping performances comparable with LiDAR DEMs? iii) Is there a significant difference in terrace mapping performances when using a Digital Terrain Model (DTM) or a Digital Surface Model (DSM)?

The objective of this paper is to assess the performances of automatic terrace mapping from DEMs obtained from a stereo pair of Pleiades images compare to LiDAR DEMs. The dataset used for the performance assessment covers a $4 \mathrm{~km}^{2}$ region of gentle, hilly Mediterranean vegetated farmland in southern France. First, the paper presents the datasets and some preliminary analysis results from the DEM comparison. The DEM processing methods, including DEM smoothing, feature extraction and vector post-processing, are discussed next. Then, the performances of both methods and the reliability of the Pleiades DEM for delineating terraces are discussed.

\section{DATASETS}

Reference terrace data, Pleiades images and a LIDAR $1 \mathrm{~m}$ DSM and DTM were acquired for a portion of the Peyne catchment (southern France) (Fig. 1). The area is mainly covered by vineyards, with small areas of cereal fields and shrubs. The elevation for the study site ranges between 50 $\mathrm{m}$ a.s.1. to about $125 \mathrm{~m}$ a.s.1.. The climate in this region is sub-humid Mediterranean, with $600 \mathrm{~mm} \mathrm{y}^{-1}$ of precipitation. Two short rainy seasons, one in the autumn and one in the spring, occur with intense rainfall. The climate and intensive vine cultivation make this area sensitive to flash flooding and erosion. Consequently, settlements from Roman times built several structures to limit floods and soil erosion, including ditches, embankments and terraces (e.g. [32]). The study site has been intensively surveyed for a long time, having been a part of an environmental observatory since 1992 (ORE OMERE: http://www.obs-omere.org/). In the study area, terraces have heights ranging from approximately $0.3 \mathrm{~m}$ to $10 \mathrm{~m}$. Their location and shape have not changed during the period of the different data acquisition dates: there were no significant modification in between 2002 (time of the LiDAR collection), and 2013 (Pleiades survey) (Fig. 1).

\section{A. Ground truth data}

A systematic field survey was conducted in 2010, with a survey rate of $1.5-3 \mathrm{~km}^{2} \mathrm{~d}^{-1}$ per person, depending on the accessibility of the terrain. The terraces were delineated with an elevation accuracy of $0.1 \mathrm{~m}$ for heights lower than $3 \mathrm{~m}$ and $0.5 \mathrm{~m}$ for elevations higher than $3 \mathrm{~m}$. Regarding the terraces height, the considered reference field survey was in some instances limited by the accessibility of the area, thus a higher accuracy cannot be expected. Because of this, in this study ground height data are used to group the field-surveyed terraces in different height classes, to project the detection results regarding the terrace height. The overall survey quality is comparable to the official information generally available about terraces locations. The surveyed features, including their location and height, were further verified and digitalized using a $0.5 \mathrm{~m}$ resolution aerial photo (BD-Ortho (CIGN) (Fig. 2).

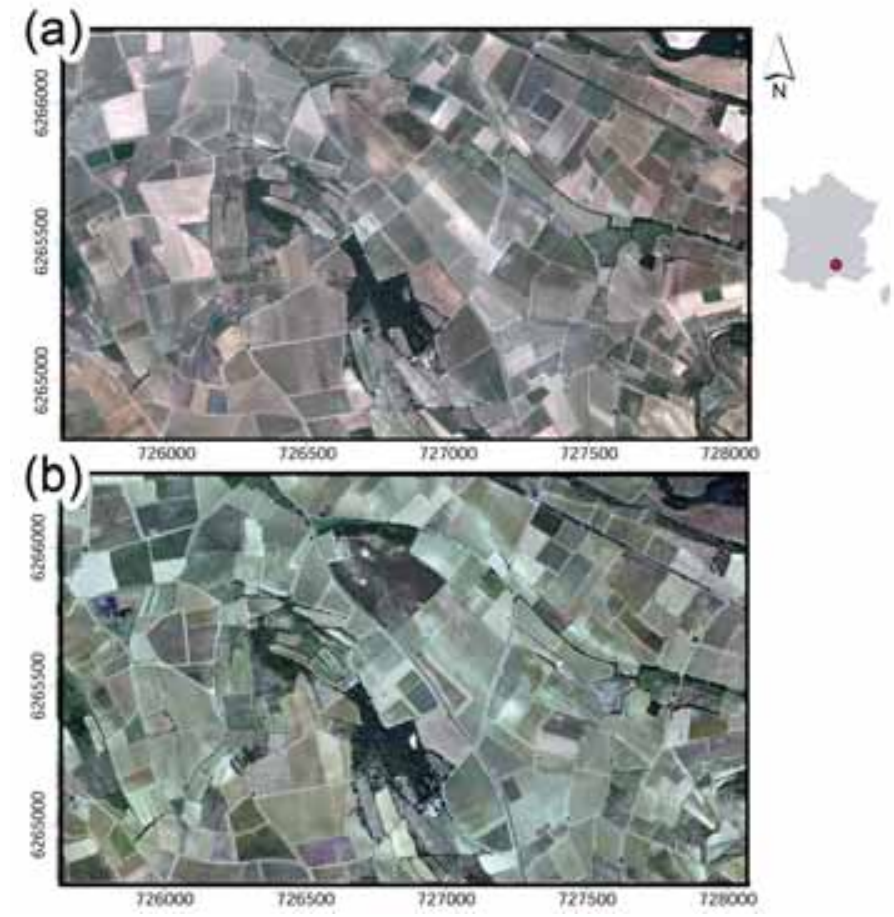

Fig. 1. Location of the study site and view of the area in 2002 (a), and 2013 (b). Images as seen on Google Earth

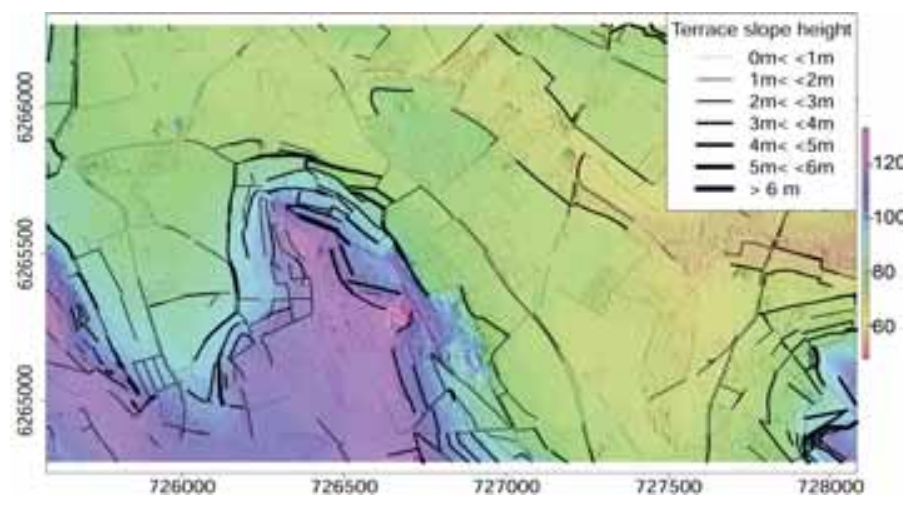

Fig. 2. Ground truth dataset overlapped to the Pleiades DSM

\section{B. Pleiades DEMs}

A Digital Surface Model (DSM) was built from a stereo pair of Pleiades images acquired during the leaves-off period of vegetation (January 2013) at a high global incidence angle (30 degrees) leading to a Base to Height $(\mathrm{B} / \mathrm{H})$ ratio of $\sim 1 / 1.6$ which is a usual ratio for stereo pair of satellite images. The DSM was produced by using the open source Mic-Mac (Multi Image Matches for Auto Correlation Methods) tool developed at the French Mapping Agency (IGN) [33], [34].

MicMac is based on the minimization of a global energy that combines a data term which is the image matching score and a regularization term.

$$
E_{\alpha}(Z)=1-\operatorname{corr}(x, y, Z(x, y))+\alpha F(\vec{G}(Z))
$$

where corr is the normalized cross correlation score at the image projections of point $(x, y, Z), F(\vec{G}(Z))$ (Eq. 2) is a 
positive function that depends on the variations of $Z$, and it is a regularization term that expresses the a priori knowledge of the surface regularity. $\alpha$ is a weighting parameter for the regularization term.

$F(\vec{G}(Z))=|(Z(x+1, y)-Z(x, y))|+|(Z(x, y+1)-Z(x, y))|$

The regularization term is well suited for high spatial resolution images since it varies with the terrain discontinuities [35]. In this study, the $\alpha$ parameter was set to be very low to maintain the terrace slopes. To deal with large areas, the MicMac method has a multi-resolution pyramidal approach, that consists in starting the computation at a coarse resolution to reduce the height search space and improving recursively the matching process at each resolution, similar to [36]. The final DSM was resampled at a resolution of $1 \mathrm{~m}$, to be comparable with the resolution of the LiDAR DEMs.

From this DSM, a DTM was generated. Terrace walls present a high local slope, and many DTM filters aim to smooth DSMs (i.e., remove slopes). Consequently, instead of using the usual slope-based filtering algorithm [37], we applied a normal closing filter with circular structural elements of $10 \mathrm{~m}$ followed by a Gaussian smoothing filter with a width of $5 \mathrm{~m}$. In mathematical morphology, the closing tends to enlarge the boundaries of foreground (bright) regions in an image (and shrink background color holes in such regions). The effect of the operator is to preserve background regions that have a similar shape to its structuring element, or that can completely contain the structuring element, while eliminating all other regions of background pixels. The choice of the structural element size was governed by the size of the removed object (i.e., vine lines, isolated trees and hedgerows). A Gaussian smoothing filter was then applied to reduce noise on the resulting map while preserving edges on the image. Consequently (Fig. 3), the obtained DTM looks less noisy than the initial DSM, and the terraces are preserved in the landscape.

The final datasets (Pleaides DSM and DTM) show no systematic error over permanent terrain structures (1.8 e-06 $\mathrm{m})$, while presenting an overall standard deviation of errors of $0.51 \mathrm{~m}$ with respect to centimetric DGPS points.

\section{Multi-echo LiDAR DEMs}

LiDAR data were acquired over the study area in June 2002 with a Falcon II Toposys LiDAR system mounted on a helicopter (flight elevation: $900 \mathrm{~m}$; laser pulse emission rate: $83 \mathrm{MHz}$; 3D points spatial sampling rate: $10 \mathrm{pts}^{-2}$ [38]). The 3D point cloud allowed the creation of a $1 \mathrm{~m} \mathrm{DTM}$ and DSM.

The DSM was computed using bi-linear interpolation of the first pulse points at the regular grid DTM node locations. The DTM was computed using the same process from the last pulse scatter of points. From the latter pulse, an additive erosion filter with an adaptive structural element size was applied to remove some residual surface objects (houses, dense forests and hedgerows). The post survey accuracy on the LiDAR last-pulses topographic points on flat and non vegetated areas

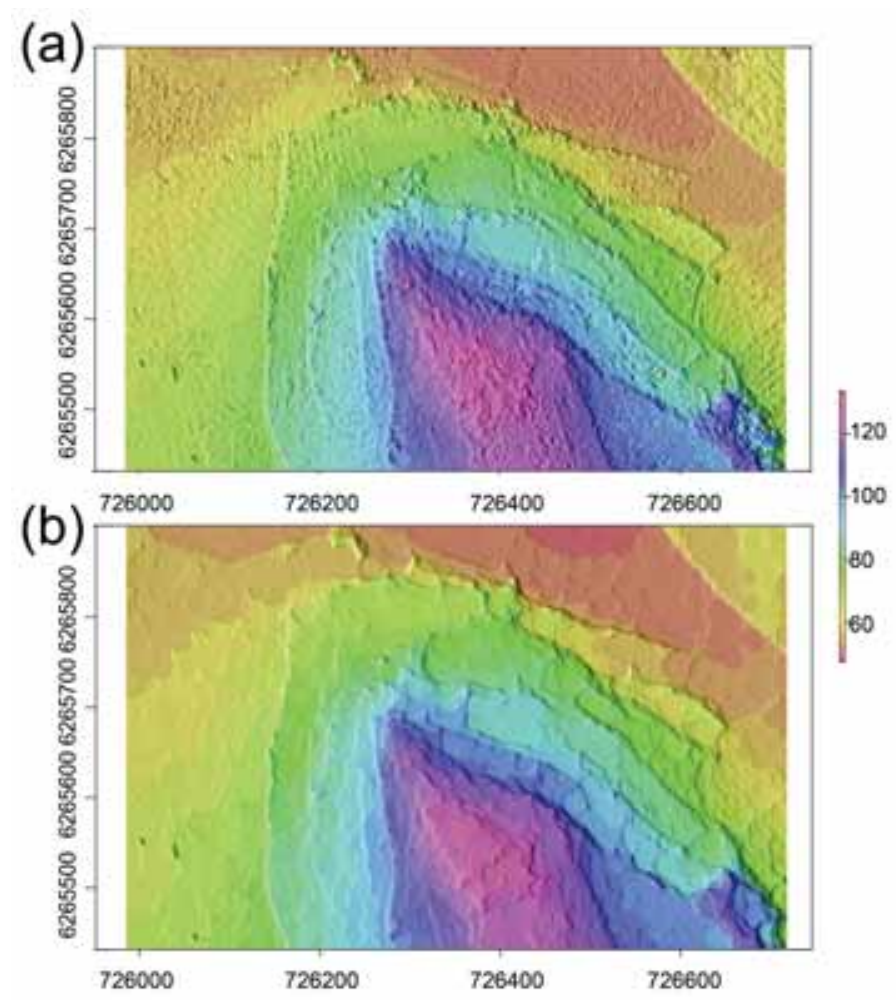

Fig. 3. Pleiades DSM to DTM process: initial DSM (a); DTM after opening and Gaussian filters (b) on a hillslope of the study area

exhibited a Gaussian noise, with a standard deviation of approximately $0.06 \mathrm{~m}$ [38] with respect to centimetric DGPS points.

\section{LiDAR and Pleiades DEMs comparison}

Because the Pleiades DSM was acquired 12 years later than the LiDAR DSM and the aim of the work is to extract the man-made structures in the landscape, the elevation of the two datasets was compared only for permanent structures (roads, ways, terraces). Due to the non-Gaussian deviation distribution with short tails, robust statistics were computed by comparing the elevations at the remaining 87000 grid nodes. The absolute median deviation between the Pleiades and LiDAR elevations was estimated to be $0.35 \mathrm{~m}$. Overall, $90 \%$ of the deviations belong to $[-1.4 \mathrm{~m},+1.1 \mathrm{~m}]$, and $50 \%$ of the deviations belong to $[-0.17 \mathrm{~m},+0.42 \mathrm{~m}]$. As pointed out by [39] the feasibility of Pleiades datasets and the quality of the derived DEMs in relation to the incidence angle depends on the context: in open landscapes without severe occlusions, the use of a single stereo pair can provide optimal results also with a fairly wide stereo angle. Giving the initial incidence angle of the considered dataset (30 degrees), despite being more noisy, the overall quality of the Pleiades derived elevation surfaces is close to that derived from the airborne DEMs. As well, despite the local scale roughness, the Pleiades DSM shows an elevation disruption for every terrace location, as shown in figure 4. 

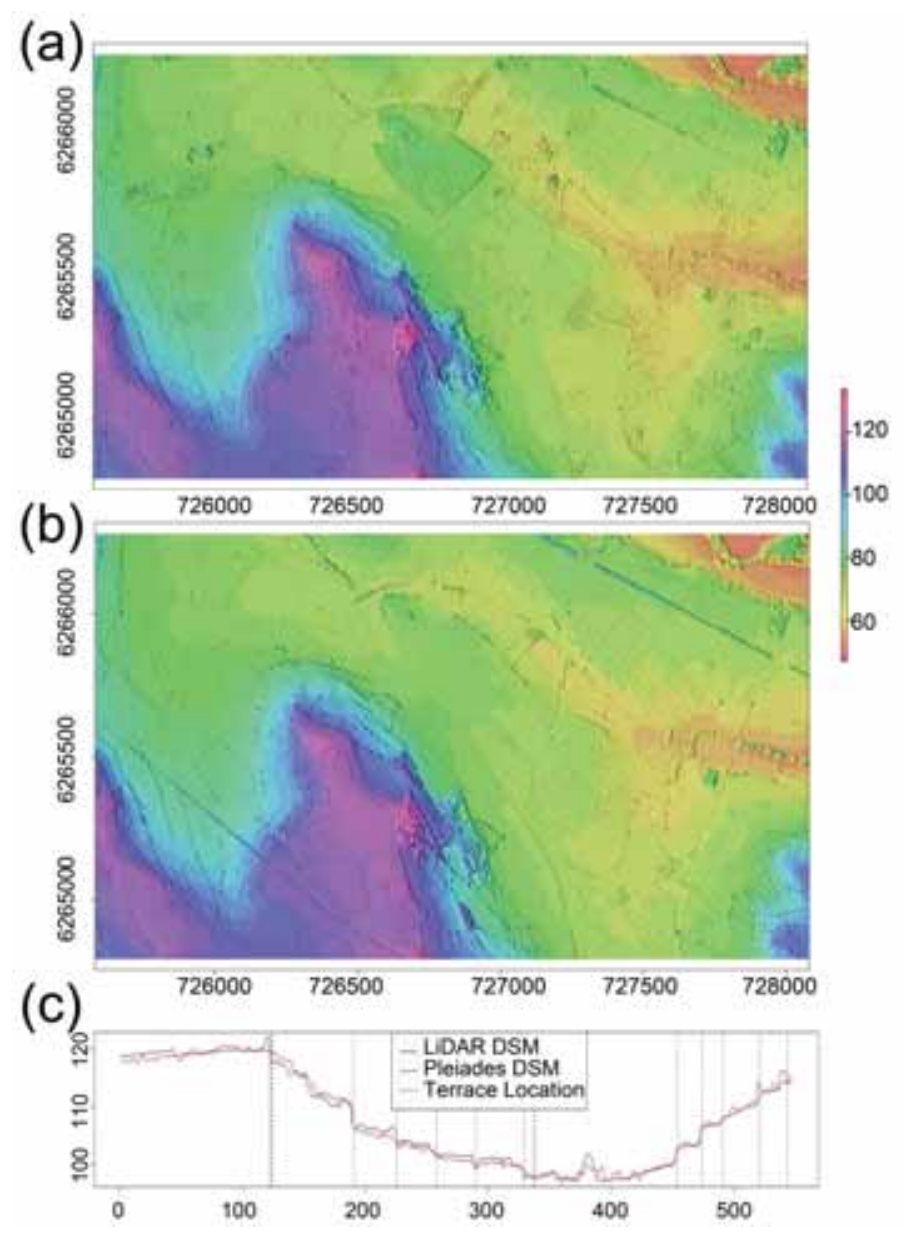

Fig. 4. Pleiades and LiDAR DSM comparison. The 2002 Lidar DSM (a) is compared to the 2013 Pleiades DSM (b). The figure also shows an elevation profile of a hill slope and the terrace locations (c)

\section{METHODS}

A. Terrace slope detection using the Fast Line Segment Detection (LSD) image processing algorithm

This detection method relies on two steps: a DTM or DSM local contrast enhancement step providing a grey level image from which a final feature extraction step (LSD) is performed (Fig. 5).
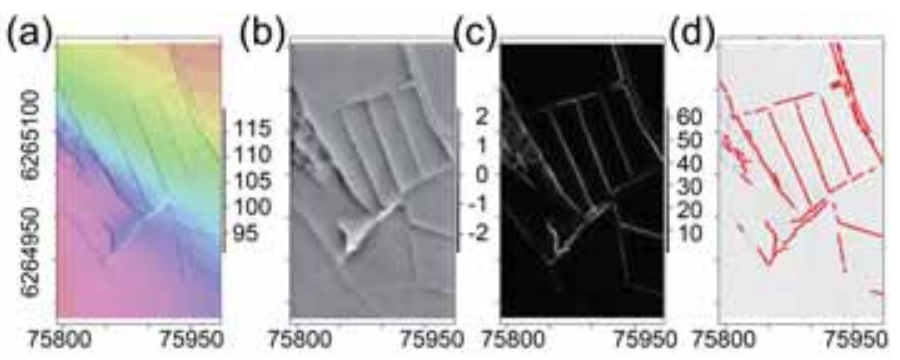

Fig. 5. LSD method: (a) original DEM, (b) DEM local contrast enhancing from a Gaussian filter, (c) Gradient magnitude image and (d) detected line segment in red

The LSD aims at detecting locally straight contours on images, with a contour being an area where the gray level is changing fast enough from dark to light or the opposite
[41]. To obtain a monochromatic image and enhance terrraces as contours, the elevation contrast of the DEM was increased by subtracting a regularised DEM after Gaussian smoothing with a radius of 10 pixels to the initial DEM (Fig. 5c).

Next, the image is processed using the Fast Line Segment Detection algorithm [40]. The following paragraphs will expose its main characteristics and parameters, despite its presentation as a parameterless method [41].

Given an image gradient (Fig. 5c), the method computes a level-line field, where level-lines are created at each pixels as vectors orthogonal to the gradient direction. The level-line field is then segmented into connected regions of pixels that have the same level-line orientation, up to a certain toleration angle $\tau$ (Fig. 6). Each region is considered as a possible line candidate. The acceptation-rejection of a region as a line segment follows the Helmholtz principle, which states that no line segment should be detected in an image of pure noise.

The acceptation-rejection relies on the following processes: i) a rectangle entirely covering each region is delineated (Fig. $6)$; ii) the center of mass of the region is used to select the center of the rectangle, and the first inertia axis is considered to select the rectangle orientation; iii) for each rectangle, the total number of pixels in the rectangle, $n$, and its number of aligned points (level-lines having their orientation within the $\tau$ tollerance), $k$, are counted; iv) for each rectangle, the score $\frac{k}{n}$ is calculated; v) this score is compared with a binomial $k$ distribution under an hypothesis $H_{0}$ of pure random angle fields (noise) with a distribution angle of $[0, \pi]$; vi) the region is accepted as a line segment when the score is rare in the $H_{0}$ distribution (low probability). This latter test is also referred to as a contrario approach [41].

In a final step, a vectorised line segment list is produced from the rectangular properties of the image coordinates.
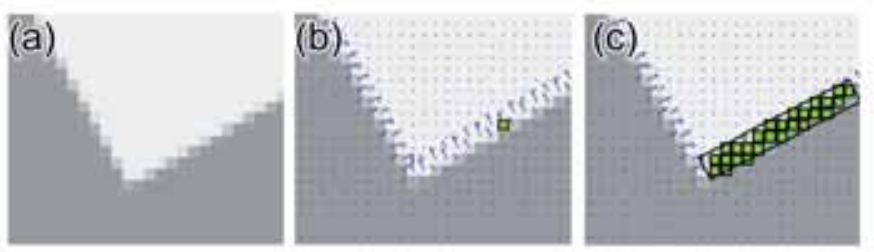

Fig. 6. Examples of a synthetic image (a) of gradient (blue) vectors, direction and magnitude (b) and a region with aligned (green) pixels on an image edge that was approximated by a rectangle (c). Images modified from [40]

Six parameters are required in the LSD algorithm: $\tau, S, q, e, d, c$. The tolerance angle $\tau$ is the first of parameter and is expressed in degrees with a default value of 22.5 as supported by tests on numerous images [40].

The scale factor $S$ controls the image size reduction and avoids some artifacts in the computation. $S$ is expected to range from 0.8 (no scaling) and up to $\infty$. The $c$ parameter controls the Gaussian kernel width (standard deviation) and is equal to $\frac{c}{S}$ with a default $c$ value of 0.6.

The $q$ parameter controls the gradient threshold $\rho=\frac{q}{\sin (\tau)}$. Pixels with gradient magnitudes smaller than $\rho$ are excluded when a region grows. $q$ is generally fixed to 2 , and should change when the image intensity range differs from the $[0,255]$ interval. 
The $e$ parameter denotes the acceptation probability threshold of the $k$ distribution under $H_{0}$. However the LSD algorithm is hardly sensitive to this parameter [41].

The last control parameter is the minimal density $d$ of the region of aligned pixels in the rectangle to be accepted. This parameter is considered in addition to the a contrario test and is expected to range from 0 to 1 . The default $d$ value was fixed to 0.5 .

The retained optimised parameter values for this study case are exposed in Table I. Only the $q$ and $e$ parameters were optimised; the other parameters were fixed with values of $\tau=$ $22.5, c=0.6, d=0.5, S=3$. In this study case, we generally selected $q=3$ in order to minimize the effect of local noise (local bumps). A higher value for $q$ was used for the LiDAR DSM. This dataset was acquired during the vines vegetative period, thus the vine rows gave high linear local gradient on the map: this high gradient was compensated by selecting the higher $q$. This was not needed for the Pleiades DSM, aquired at the non-vegetative period.

\begin{tabular}{lll}
\hline $\begin{array}{l}\text { LSD } \\
\text { parameters }\end{array}$ & $q$ & $e$ \\
\hline LiDAR dtm & 3 & 20 \\
LiDAR dsm & 8 & 20 \\
Pleiades dtm & 3 & 80 \\
Pleiades dsm & 3 & 80
\end{tabular}

TABLE I

LSD PARAMETER VALUES

\section{B. Terrace slope detection using a geomorphometric algo- rithm}

Physical processes and anthropic elements leave important topographic signatures that can be studied using distribution analysis. In addition, recent literature has underlined how statistical analyses along with LiDAR derived topographic parameters facilitate the objective recognition of different types of landscape features and processes (e.g. [42], [43]). For this study, we applied the feature extraction technique proposed by [44] and effectively tested by [4] for identifying terrace walls. According to this approach, the surface morphology is approximated by a quadratic function (Eq. 3).

$$
z=a x^{2}+b y^{2}+c x y+d x+e y+f
$$

where $x, y, z$ are local coordinates, and $a$ through $f$ are quadratic coefficients.

Any terrace wall represents a ridge on the side of the hill; therefore, the maximum curvature $C_{\max }$ (Eq. 4) can be considered as an optimal parameter. $C_{\max }$ is derived by solving and differentiating equation 3 within a local moving window as follows [45]:

$$
C_{\max }=k g\left(-a-b+\sqrt{(a-b)^{2}+c^{2}}\right)
$$

where $k$ denotes the size of the moving window and $g$ denotes the DEM resolution.

Anthropogenic elements such as terrace slopes present clearly defined boundaries with much sharper shapes than natural terrain features. Consequently, these elements can be identified as outliers in the positive tail of the $C_{\max }$ distribution [44]. Considering a robust statistic approach [46], these elements can be identified as outliers of a whisker plot, as the points verifying equation 5 .

$$
C_{\max }>Q_{3}+1.5 I Q
$$

where $Q_{3}$ and $I Q$ respectively denote the 3rd quartile and inter-quartile distance of the $C_{\max }$ distribution.

The thresholding approach (Eq. 5) produces a raster map of the potential terraces. To calculate the vector map of the terraces that correspond to the raster centerline, we use a method that is similar to the one proposed by [47]. This approach is based on the Marr-Hildreth technique [48] and is less computationally intensive than other methods [49]. The algorithm divides the raster into subsets of $100 \times 100$ pixels that are processed simultaneously and in parallel. For each subset, the algorithm focuses on each extracted region of pixels and processes it using the following steps. (i) Determining the Euclidean distance from each feature pixel to the nearest background pixel. (ii) The distance map is convolved with a bidirectional Laplacian filter in a manner similar to that of the Marr-Hildreth edge detection algorithm [48]. (iii) To obtain the centerline, [47] suggests using a threshold between 0.7 and 0.9 to apply to the output of the Laplacian convolution. Anything below this threshold is considered part of the centerline. The authors noted that the threshold value has little impact on the final line. However, the threshold is important for ensuring the continuity of the centerline, with a higher value resulting in a more robust centerline calculation. After the different trials in this study, we considered 0.5 as the optimal threshold. (iv) The final centerline can be more than one pixel wide; therefore, the produced output is further thinned to reduce the centerline to a width of one pixel and the final centerline is converted into a vector line.

\section{Detection performance analysis}

Quantitative assessments of the terrace slope detection methods were performed using the buffer method, initially proposed by [50] to quantify road detection performances. This method matches the overlapping of the detected and reference vectorised network, with performance metrics based on network lengths. In addition, this method can be applied to either a connected or unconnected network, which is the case for a terrace slope network. More specifically, this method measures the length of the detected network included $\left(T P_{1}\right)$ or not included in the reference domain and the length of the reference network included $\left(T P_{2}\right)$ or not included in the detected domain. The domains are defined as buffers around the two networks. The width of the buffer is the only required parameter, which was fixed to $10 \mathrm{~m}$ to account for the planimetric accuracies of each dataset.

First, three usual performance metrics are computed from the matching: the true positive metric $(T P)$, which is the average between $T P_{1}$ and $T P_{2}$; the true negative $T N$ (omission), which is the length of the reference not included in the detected network domain, and the false positive FP (commission), 
which is the length of the extracted network not included in the reference domain. These metrics are normalised to the total length of the reference network to a range of $[0,1]$.

An additive performance metric stemming from the previous metrics provide a quantitative assessment of the terrace detection, which makes an objective comparison between several detection methods possible [51]. This metric, also named quality index, $Q I$, ranges from 0 (lowest quality) to 1 (highest quality) (Eq. 6).

$$
Q I=\frac{T P}{T P+T N+F P}=\frac{T P}{1+F P}
$$

Finally, because terrace slopes are exclusively located at the borders of agricultural fields and because plot databases are frequently available, performance metrics were computed from the raw terrace segment lists out of the detection methods and from reduced lists, excluding the terrace segments that were located far away (10 meters) from the plot border lattice. This consideration only changes the $F P$ statistic computation. Furthermore, FP1 denotes the $F P$ metric computed for reduced lists and FP2 denotes the $F P$ metric computed for the raw complete list.

\section{RESUlts}

\section{A. Detection performance results: LiDAR DEMs}

The performance metrics of the terraces delineation from LiDAR DSM and DTM are exposed in table II. The results showed that at least $95 \%$ to $98 \%$ of the terrace slopes were detected on DTM, regardless of the method. The LSD method is producing fewer commissions and providing the highest quality index value. Figure 7 shows that $T N$ occurs in the LiDAR DTM when using the LSD method on flat areas where the terraces slopes have low heights. Similarly, FP occurs on the LiDAR DTM using the LSD method on i) the steepest slopes, where bushes and hedgerows can perturb the accuracy of the DTM, and ii) along main roads and down to the streams in areas where river or ditch banks can be confused with terrace slopes. Similar behaviour can be observed when using the geomorphometric method. The results in table II show similar and high raw commissions when using the LSD and geomorphometric methods. However, commissions are highly reduced thanks to the plot border filter post-processing.

When applying the methods to the LIDAR DSM, the detection performances were reduced with true positive rates of approximately $75 \%$ for both methods. However, the geomorphometric method slightly outperforms the LSD method when applied to LiDAR DSM. This result suggests that the geomorphometric method may be more robust when applied to noisy DEM.

\begin{tabular}{lllllll}
\hline Method & $\begin{array}{l}\text { DEM } \\
\text { Type }\end{array}$ & TP & TN & $\begin{array}{l}\text { FP } \\
\mathbf{1}\end{array}$ & $\begin{array}{l}\text { FP } \\
\mathbf{2}\end{array}$ & $\begin{array}{l}\text { QI } \\
(\mathbf{1})\end{array}$ \\
\hline LSD & dtm & 0.95 & 0.05 & 0.20 & 0.33 & $\mathbf{0 . 7 9}$ \\
LSD & dsm & 0.75 & 0.25 & 0.40 & 0.61 & $\mathbf{0 . 5 4}$ \\
Curv & dtm & 0.98 & 0.02 & 0.36 & 0.68 & $\mathbf{0 . 7 2}$ \\
Curv & dsm & 0.76 & 0.24 & 0.31 & 0.70 & $\mathbf{0 . 5 8}$ \\
& \multicolumn{5}{c}{ TABLE II } &
\end{tabular}

DETECTION PERFORMANCES OF THE LIDAR DATASETS
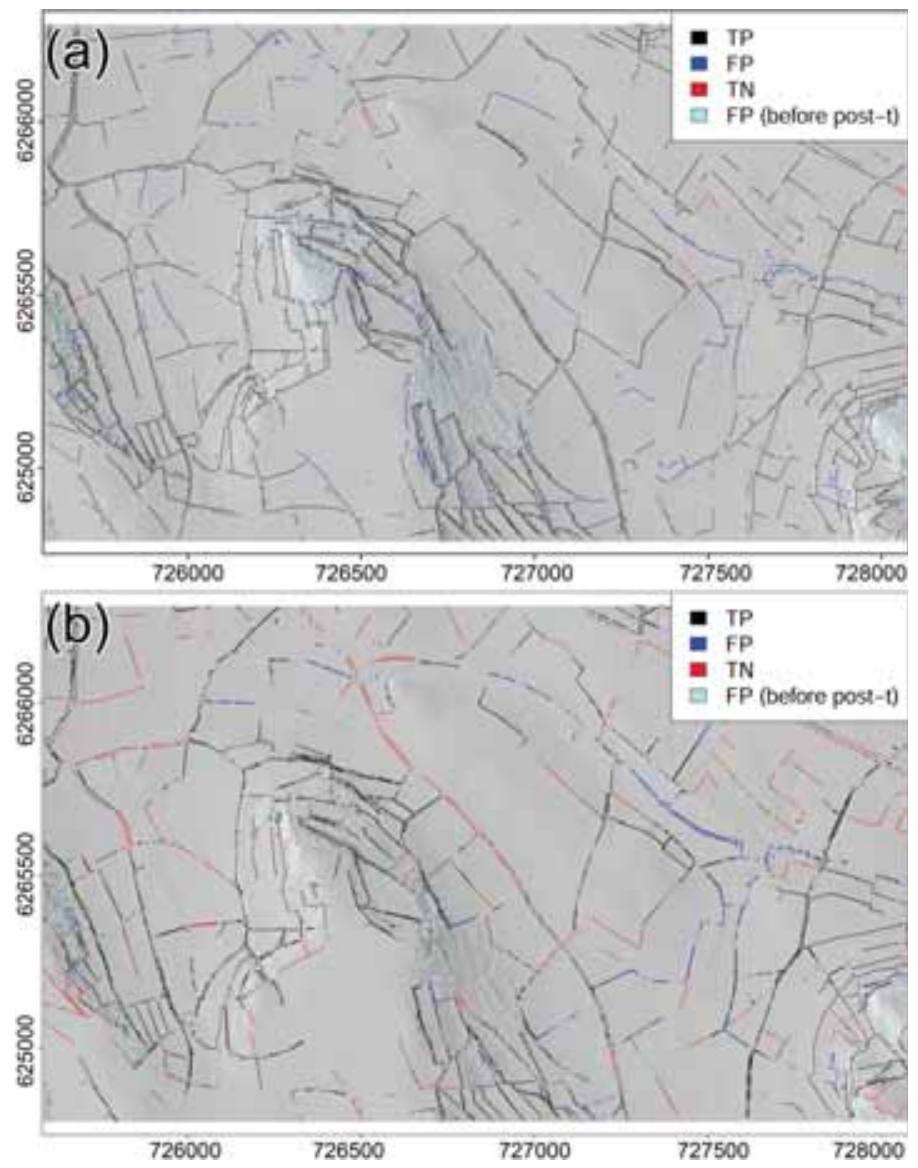

Fig. 7. Maps of the detected terraces using the LiDAR DTM and the geomorphometric method (a) or the LDS method (b). Resulting $T P$ elements in black, $T N$ elements in red, filtered $F P$ elements in blue and non filtered FP elements in light blue

\section{B. Detection performance results: Pleiades DEMs}

Table III shows the performance metrics of terrace slope delineation from the Pleiades DSM and DTM.

\begin{tabular}{lllllll}
\hline Method & $\begin{array}{l}\text { DEM } \\
\text { Type }\end{array}$ & TP & TN & $\begin{array}{l}\text { FP } \\
\mathbf{1}\end{array}$ & $\begin{array}{l}\text { FP } \\
\mathbf{2}\end{array}$ & $\begin{array}{l}\text { QI } \\
(\mathbf{1})\end{array}$ \\
\hline LSD & dtm & 0.62 & 0.38 & 0.23 & 0.68 & $\mathbf{0 . 5 0}$ \\
LSD & dsm & 0.44 & 0.56 & 0.20 & 0.58 & $\mathbf{0 . 3 7}$ \\
Curv & dtm & 0.65 & 0.35 & 0.26 & 0.79 & $\mathbf{0 . 5 2}$ \\
Curv & dsm & 0.50 & 0.50 & 0.22 & 0.87 & $\mathbf{0 . 4 1}$ \\
& \multicolumn{5}{c}{ TABLE III } \\
\end{tabular}

The results show that only $65 \%$ of the terrace slopes are detected on the Pleiades DTM when using the geomorphometric method. The LSD method is producing slightly fewer commissions if compared with the geomorphometric method, but at the same time it provides less TP values. In general, the detection performance is systematically lower $(-15 \%)$ using the Pleiades DSM. Commissions are numerous, but the results are however improved using the plot border filter postprocessing. Results on the Pleiades DTM shows quite similar performances using the LSD or the geomorphometric method. The geomorphometric method, however, outperforms the LSD method when applied on the Peiades DSM: for this dataset, 
the LSD seems very sensitive to DEM noise. Similarly to the LiDAR results, Figure 8 shows that $T P$ occurs in the Pleiades DTM when using the geomorphometric method on the steepest slopes where terrace slopes are tall. FPs occur in the Pleiades DTM when using the geomorphometric method on areas where bushes and hedgerows can perturb terrace slope representation, expecially along plot borders.
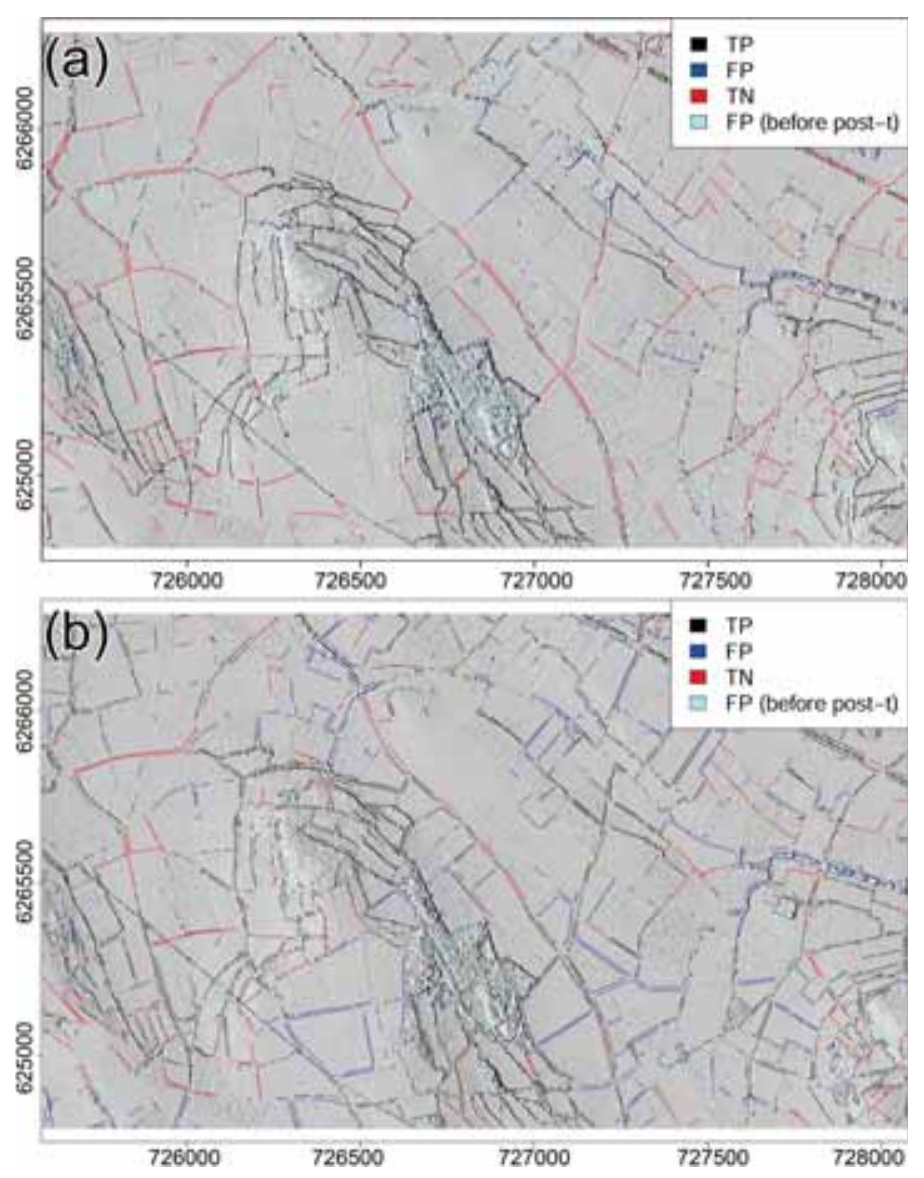

Fig. 8. Maps of the detected terraces using the Pleiades DSM and the geomorphometric method (a) or the LDS method (b).Resulting $T P$ elements in black, $T N$ elements in red, filtered $F P$ elements in blue and non filtered $F P$ elements in light blue

However, except when using the LSD method in the Pleiades DSM, the detection rate is always higher than 70 $\%$ when the terrace height is greater than $3 \mathrm{~m}$ (Fig. 9). The detection rate of the terrace heights is greater than $3 \mathrm{~m}$ and is at least $80 \%$ when using LiDAR or the Pleiades DTM. Figure 9 also clearly shows that the LSD method fails in terrace slope detection when using the Pleiades DSM, regardless of the slope height.

\section{DISCUSSION}

\section{A. Pleiades vs LiDAR performances}

The effectiveness of Pleiades for extracting anthropogenic features has been proved in other studies, mainly for building detection [27]. However, this study shows that the very high spatial resolution of the datasets allows the detection of smaller features on the earth's surface, such as terraces with heights comparable to the DEM resolution (1m). Pleiades

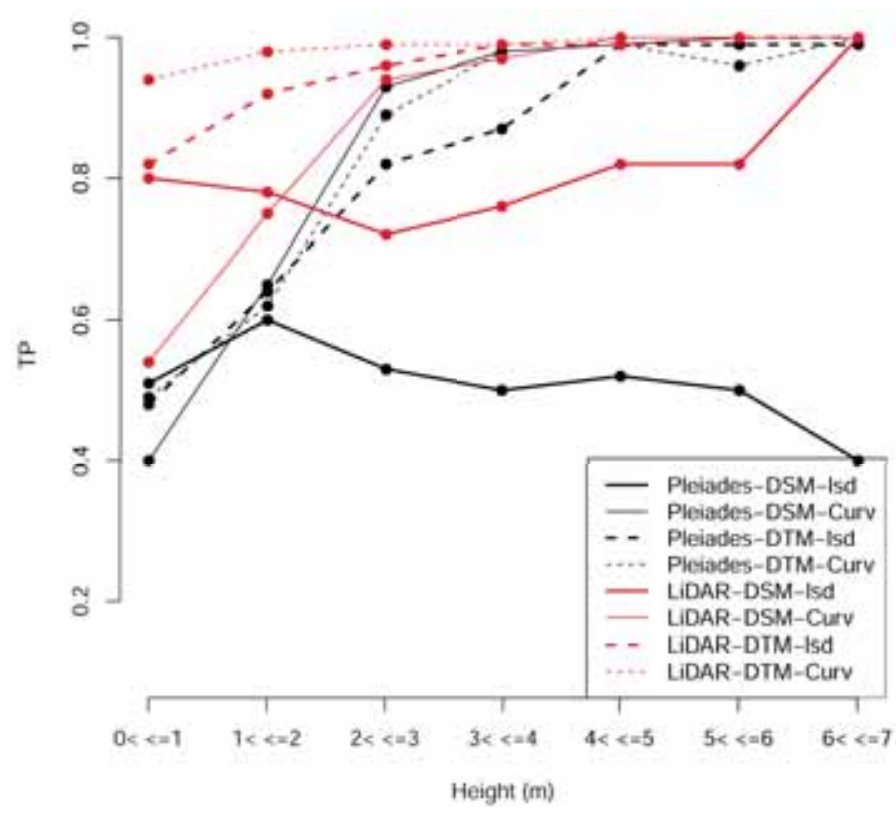

Fig. 9. Detection rate $(T P)$ as a function of the terrace height

DTMs provide results that are comparable with the analyses performed with LiDAR DSMs. On the other hand, Pleiades DSMs have a slightly lower performance that is, however, comparable with other referenced LiDAR DTM analyses of more complex features under vegetation cover in mountainous areas [52]. This latter point can be explained by the roughness of the models. In the Pleiades DSM, being derived from satellite images, the morphology of specific features can be masked by the presence of objects on the ground as well as by their shadows. In addition, the incidence angle of the satellite might have influenced the quality of the dataset: even if the overall median difference between the LiDAR and the Pleiades datasets is low $(35 \mathrm{~cm})$, locally, there might be a local loss of resolution as well as some spatial artefacts induced by the incidence angle, causing the lower accuracy of the extraction mainly due to a lower completeness of the extracted features (higher number of TNs and lower number of TPs if compared to the average values of LiDAR DSMs). The size of the analysed features (height) is only slightly important when considering LiDAR DTMs and the effectiveness of detections (TPs): both the geomorphometric and the LSD algorithm quality converge when the features tend to increase in size. By contrast, when using noisy datasets (LiDAR DSM or Pleiades DEMs) the feature size is important for determining the effectiveness of the extractions, especially when using the geomorphometric approach. Specifically, when features are greater than approximately $3 \mathrm{~m}$, the rate of TPs is similar for the LiDAR and Pleiades datasets. In our case, for local slope discontinuities (terraces), their vertical position in the Pleiades dataset may be underestimated due to a lower correlation scores especially with a high $\mathrm{B} / \mathrm{H}$ ratio, however, the terraces are well localized in the image and this is sufficient for the proposed application: overall, the performances of the Pleiades DSMs are comparable with those of the LiDAR DSMs. However, the Pleiades system allows wider coverage 
of approximately $100 \times 100 \mathrm{~km}^{2}$, which can be acquired by the satellite from the same orbit, and offers a new tool for large scales applications when compared with LiDAR DEMs.

\section{B. Automatic mapping of terraces}

Previous research regarding the extraction of features using curvature on LiDAR DTMs highlights how curvature can produce results with high branching (higher number of FP), which corresponds with greater extraction completeness [44]. Similar conclusions can be drawn when considering LiDAR DTMs and the proposed geomorphometric method, which produces a higher number of TPs and lower TN values when compared with the LSD method. When using the same topographic information, the geomorphometric method performs better when the terraces are less than $3 \mathrm{~m}$ tall and produces a slightly lower number of omissions. This result corresponds with the findings of [44], which underline how using curvature could be better for identifying smaller features. The use of algorithms based on the linearity of features (LSD) rather than on their convexity (geomorphometric) appears to work in the presence of more clean datasets (DTMs), independently of the considered remote sensor (LiDAR vs Pleiades). Linear detection provides a slightly higher reliability for neat datasets from LiDAR (DTMs).

\section{Future challenges: DSM or DTM, filtering problems, ad- ditional required processing, dataset resolution}

Considering the results in Table II and III and the performances displayed in Figure 8, the use of DTMs seems more appropriate when using LiDAR surveys and photogrammetry from Pleiades. Generally, DSMs are too noisy for comparable feature detection, but they produce good results if compared to other works in literature based on different sources and landscapes (e.g. DTMs from LiDAR [52], [53]). However, if features are large enough (generally higher than $3 \mathrm{~m}$ ), the use of the geomorphometric approach gives good and comparable results using DSMs and DTMs. For this work the only post-processing procedure considered was a filter based on the plot border. Further improvements could be obtained, especially when using the geomorphometric approach. For example, the skeletonisation process could be improved and the looping and branching of the vector map could be reduced. In addition, using a pre-processing filter on the DSMs (median filter, or Gaussian filter, for example) could reduce the noise improving the performance of the algorithms. Further, to test the full Pleiades performances, it will be interesting to evaluate terraces extraction using the full resolution DSMs (smaller than $1 \mathrm{~m}$, in some areas), to investigate the effect of noises (due to errors or surface roughness) on higher resolution DEMs (similarily to what has been done in [53]-[55]) when comparing extracted features with the ground truth datasets. These points are still open for future research.

\section{CONCLUSION}

Three major results were obtained from this study. From the algorithm point of view, the analysis underlined that the geomorphometric algorithm is generally more robust than the LSD algorithm when applied to noisy DEMs. This information could be usefull in general also for other researches dealing with feature extractions from DEMs from multiple sources. Considering the topographic information, the automatic mapping of terraces from Pleiades DEMs is reliable for terraces that are higher than $2 \mathrm{~m}$, also thanks to a post-process filter to avoid commissions far away from the plot boundaries. LiDAR detection performances are systematically higher than the Pleiades performances, especially when using a DTM. However, the filtering of the Pleiades DSMs and the successive creation of DTMs seems to give promising results, expecially considering the wider coverage that can be obtained by this dataset compared to the LiDAR coverage.

\section{ACKNOWLEDGMENT}

The authors would like to thank the French Space Agency CNES and Airbus Defense \& Space for providing the Pleiades Images within the RCT Pleiades program. In addition, the authors would like to thank IGN-Espace, especially Mr. Nicolas Champion, for helping generate Pleiades DEMs from image pairs. Resources for the geomorphometric method computation were provided by the Interdepartmental Research Centre of Geomatics CIRGEO- at the University of Padova (Italy).

\section{REFERENCES}

[1] J. Zalasiewicz, A. Smith, M. Hounslow, M. Williams, A. Gale, J. Powell, C. Waters, T. Barry, P. Bown, P. Brenchley, D. Cantrill, P. Gibbard, F. Gregory, R. Knox, J. Marshall, M. Oates, P. Rawson, P. Stone, and N. Trewin, "Are we now living in the Anthropocene.," GSA Todayvol. 18, no. 2, 2008

[2] J. Zalasiewicz, C. N. Waters, and M. Williams, "Human bioturbation, and the subterranean landscape of the Anthropocene," Anthropocene, vol. 6, pp. 3-9, 2014.

[3] A. G. Brown, S. Tooth, R. C. Chiverrell, J. Rose, D. S. G. Thomas, J. Wainwright, J. E. Bullard, V. R. Thorndycraft, R. Aalto, and P. Downs, "The Anthropocene: is there a geomorphological case?," Earth Surface Processes and Landforms, vol. 38, no. 4, pp. 431-434, 2013.

[4] P. Tarolli, F. Preti, and N. Romano, "Terraced landscapes: From an old best practice to a potential hazard for soil degradation due to land abandonment," Anthropocene, vol. 6, pp. 10-25, 2014.

[5] P. Tarolli and G. Sofia, "Human topographic signatures and derived geomorphic processes across landscapes," Geomorphology, 2016.

[6] A. Bevan and J. Conolly, "Terraced fields and Mediterranean landscape structure: An analytical case study from Antikythera, Greece," Ecological Modelling, vol. 222, pp. 1303-1314, 2011.

[7] European Commission, "The Common Agricultural Policy a Partnership between Europe and Farmers," Directorate General Agriculture and Rural Development. Publications Office of the European Union, 2012.

[8] T. Douglas, D. Critchley, and G. Park, "The deintensification of terraced agricultural land near trevelez, sierra nevada, spain," Global Ecology and Biogeography Letters, pp. 258-270, 1996.

[9] J. Lesschen, L. Cammeraat, and T. Nieman, "Erosion and terrace failure due to agricultural land abandonment in a semi-arid environment," Earth Surface Processes and Landforms, vol. 33, no. 10, pp. 1574-1584, 2008.

[10] J. Dover, T. Sparks, S. Clarke, K. Gobbett, and S. Glossop, "Linear features and butterflies: the importance of green lanes," Agriculture, ecosystems \& environment, vol. 80, no. 3, pp. 227-242, 2000.

[11] J. Blondel, "The design of mediterranean landscapes: a millennial story of humans and ecological systems during the historic period," Human Ecology, vol. 34, no. 5, pp. 713-729, 2006.

[12] R. Z. Wheaton, Terracing as a Best Management Practice for Controlling Erosion and Protecting Water Quality. Purdue University, Cooperative Extension Service, 2001.

[13] D. W. Hallema and R. Moussa, "A model for distributed giuh-based flow routing on natural and anthropogenic hillslopes," Hydrological Processes, vol. 28, pp. 4877-4895, 2013. 
[14] R. Cots-Folch, J. A. Martínez-Casasnovas, and M. C. Ramos, "Agricultural trajectories in a Mediterranean mountain region (Priorat, NE Spain) as a consequence of vineyard conversion plans," Land Degradation \& Development, vol. 20, pp. 1-13, 2009.

[15] E. Cammeraat, R. van Beek, and A. Kooijman, "Vegetation Succession and its Consequences for Slope Stability in SE Spain," Plant and Soil, vol. 278, pp. 135-147, 2005.

[16] M. Koulouri and C. Giourga, "Land abandonment and slope gradient as key factors of soil erosion in Mediterranean terraced lands," CATENA, vol. 69, pp. 274-281, 2007.

[17] J. P. Lesschen, L. H. Cammeraat, and T. Nieman, "Erosion and terrace failure due to agricultural land abandonment in a semi-arid environment," Earth Surface Processes and Landforms, vol. 33, no. 10, pp. 1574-1584, 2008.

[18] P. Tarolli, G. Sofia, S. Calligaro, M. Prosdocimi, F. Preti, and G. Dalla Fontana, "Vineyards in terraced landscapes: new opportunities from lidar data," Land Degradation and Developement, vol. 26, pp. 92-102, 2015.

[19] J. Arnáez, N. Lana-Renault, T. Lasanta, P. Ruiz-Flaño, and J. Castroviejo, "Effects of farming terraces on hydrological and geomorphological processes. A review," CATENA, vol. 128, pp. 122-134, 2015.

[20] G. Sofia, F. Marinello, and P. Tarolli, "A new landscape metric for the identification of terraced sites: the slope local length of auto-correlation (sllac)," ISPRS Journal of Photogrammetry and Remote Sensing, vol. 96, pp. 123-133, 2014

[21] F. Gallart, P. Llorens, and J. Latron, "Studying the role of old agricultural terraces on runoff generation in a small mediterranean mountainous basin," Journal of Hydrology, vol. 159, no. 1-4, pp. 291 - 303, 1994.

[22] F. Levavasseur, Structure du paysage et fonctionnement hydrologique. Application aux réseaux de fossés en zone viticole méditerranéenne. PhD thesis, Montpellier Supagro - École Doctorale SIBAGHE, 2012.

[23] S. Price and L. Nixon, "Ancient Greek agricultural terraces: Evidence from texts and archaeological survey," American Journal of Archaeology, vol. 109, no. 4, pp. 665-694, 2005.

[24] T. V. D. Sluis, T. Kizos, and B. Pedroli, "Landscape Change in Mediterranean Farmlands: Impacts of Land Abandonment on Cultivation Terraces in Portofino (Italy) and Lesvos (Greece)," Journal of Landscape Ecology, vol. 7, pp. 23-44, 2014.

[25] J.-S. Bailly and F. Levavasseur, "Potential of linear features detection in a mediterranean landscape from $3 \mathrm{~d}$ vhr optical data: application to terrace walls," in IGARSS, (Munich, Germany), pp. 7110-7113, 2012.

[26] R. Diaz-Varela, P. J. Zarco-Tejada, V. Angileri, and P. Loudjani, "Automatic identification of agricultural terraces through object-oriented analysis of very high resolution dsms and multispectral imagery obtained from an unmanned aerial vehicle," Journal of environmental management, vol. 134, pp. 117-126, 2014.

[27] D. Poli, F. Remondino, E. Angiuli, and G. Agugiaro, "Radiometric and geometric evaluation of GeoEye-1, WorldView-2 and Pléiades1A stereo images for 3D information extraction," ISPRS Journal of Photogrammetry and Remote Sensing, vol. 100, pp. 35-47, 2015.

[28] M. Bernard, David, Decluseau, L. Gabet, and P. Nonin, "3d capabilities of pleiades satellite," International archives of the photogrammetry. Remote Sens Spat Inf Sci, vol. 39, pp. 553-557, 2012.

[29] K. Jacobsen and H. Topan, "Dem generation with short base length Pleiades triplet," The International Archives of the Photogrammetry, Remote Sensing and Spatial Information Sciences, vol. XL-3/W2, pp. PIA15+HRIGI15, 2015.

[30] P. Tarolli, "High-resolution topography for understanding earth surface processes: Opportunities and challenges," Geomorphology, vol. 216, pp. 295-312, 2014.

[31] A. Baudoin, E. Boussarie, P. Damilano, G. Rum, and F. Caltagirone, "Pléiades: A multi mission and multi co-operative program," Acta Astronautica, vol. 51, pp. 317-327, 2002.

[32] A. Temple-Boyer, J.-F. Richard, and P. Arnould, "Segmenter les paysages de l'eau : une methode pour l'interpratation hydrodynamique des paysages (Dorsale tunisienne)," Science et changements planétaires / Sécheresse, vol. 18, pp. 149-160, 2007.

[33] M. Pierrot-Deseilligny and N. Paparoditis, "A multiresolution and optimization-based image matching approach: An application to surface reconstruction from spot5-hrs stereo imagery," in In: Proc. of the ISPRS Conference Topographic Mapping From Space (With Special Emphasis on Small Satellites), ISPRS, 2006.

[34] M. Pierrot-Deseilligny, L. De Luca, and F. Remondino, "Automated Image-Based Procedures for Accurate Artifacts 3D Modeling and Orthoimage Generation," Geoinformatics FCE CTU, vol. 6, pp. 291-299, 2011 .

[35] A.-M. Rosu, M. Pierrot-Deseilligny, A. Delorme, R. Binet, and Y. Klinger, "Measurement of ground displacement from optical satellite image correlation using the free open-source software MicMac," ISPRS Journal of Photogrammetry and Remote Sensing, vol. 100, pp. 48-59, 2015.

[36] H. Hirschmüller, "Stereo processing by semiglobal matching and mutual information.," IEEE transactions on pattern analysis and machine intelligence, vol. 30, pp. 328-41, 2008.

[37] G. Vosselman, "Slope based filtering of laser altimetry data," International Archives of Photogrammetry and Remote Sensing, vol. 33, no. B3/2; PART 3, pp. 935-942, 2000.

[38] J.-S. Bailly, P. Lagacherie, C. Millier, C. Puech, and P. Kosuth, "Agrarian landscapes linear features detection from lidar: application to artificial drainage networks," International Journal of Remote Sensing, vol. 29(12), pp. 3489-3508, 2008

[39] M. Bernard, D. Decluseau, L.Gabet, P. Nonin, “3D capabilities of pleiades satellite," International Archives of the Photogrammetry, Remote Sensing and Spatial Information Sciences, vol. XXXIX, no. B3, 2012.

[40] R. G. Von Gioi, J. Jakubowicz, J.-M. Morel, and G. Randall, "Lsd: A fast line segment detector with a false detection control," IEEE Transactions on Pattern Analysis and Machine Intelligence, vol. 32, no. 4, pp. 722732, 2010.

[41] R. G. Von Gioi, A Contrario Line Segment Detection. Springer, 2014.

[42] G. Sofia, F. Marinello, and P. Tarolli, "Metrics for quantifying anthropogenic impacts on geomorphology: road networks," Earth Surface Processes and Landforms, 2015.

[43] G. Sofia, P. Tarolli, F. Cazorzi, and G. Dalla Fontana, "Downstream hydraulic geometry relationships: Gathering reference reach-scale width values from LiDAR," Geomorphology, vol. 250, pp. 236-248, 2015.

[44] G. Sofia, G. D. Fontana, and P. Tarolli, "High-resolution topography and anthropogenic feature extraction: testing geomorphometric parameters in floodplains," Hydrological Processes, vol. 28, no. 4, pp. 2046-2061, 2014.

[45] J. Wood, The geomorphological characterisation of digital elevation models. PhD thesis, University of Leicester, 1996.

[46] J. W. Tukey, "Exploratory data analysis," 1977.

[47] T. M. Pavelsky and L. C. Smith, "RivWidth: A Software Tool for the Calculation of River Widths From Remotely Sensed Imagery," Geoscience and Remote Sensing Letters, IEEE, vol. 5, pp. 70-73, 2008.

[48] D. Marr and E. Hildreth, "Theory of Edge Detection," Proceedings of the Royal Society of London B: Biological Sciences, vol. 207, pp. 187-217, 1980

[49] D. Ziou and S. Tabbone, "Edge Detection Techniques - An Overview," International Journal of Pattern Recognition and Image Analysis, vol. 8, pp. 537-559, 1998.

[50] C. Heipke, H. Mayer, C. Wiedemann, and O. Jamet, "Evaluation of automatic road extraction," International Archives of Photogrammetry and Remote Sensing, vol. 32, no. 3 SECT 4W2, pp. 151-160, 1997.

[51] I. Molly and T. Stepinski, "Automatic mapping of valley networks on mars," Computers \& Geosciences, vol. 33, pp. 728-728, 2007.

[52] C.-W. Lin, C.-M. Tseng, Y.-H. Tseng, L.-Y. Fei, Y.-C. Hsieh, and P. Tarolli, "Recognition of large scale deep-seated landslides in forest areas of Taiwan using high resolution topography," Journal of Asian Earth Sciences, vol. 62, pp. 389-400, 2013.

[53] P. Tarolli, G. Sofia, and G. Dalla Fontana, "Geomorphic features extraction from high-resolution topography: landslide crowns and bank erosion," Natural Hazards, vol. 61, no. 1, pp. 65-83, 2012.

[54] F. Pirotti, P. ,Tarolli, "Suitability of LiDAR point density and derived landform curvature maps for channel network extraction," Hydrol. Process, vol. 24, pp. 11871197, 2010

[55] G. Sofia, F. Pirotti, P. ,Tarolli, "Variations in multiscale curvature distribution and signatures of LiDAR DTM errors," Earth Surface Processes and Landforms, vol. 38, pp. 11161134, 2013. 


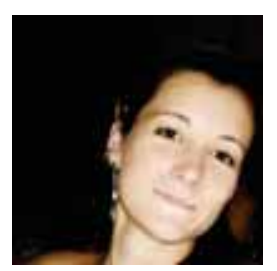

Giulia Sofia Giulia Sofia is a Post-Doctoral Research Associate at the Department of Land, Environment, Agriculture and Forestry-University of Padova (Italy). She received a B.S. and M.S. in Forestry Science, and a Ph.D. degree (2012) in Water Resources, Soil Conservation and Watershed Management from the University of Padova (Italy). Her area of research is geomorphology and digital terrain analysis, with a special interest in feature extraction from high resolution topography. Her recent research interest concerns anthropogenic landscapes, incorporating the related human-induced processes. http://scholar.google.it/citations?user=0iNjLMAAAAJ\&hl=it, http://orcid.org/0000-0002-9769-439X

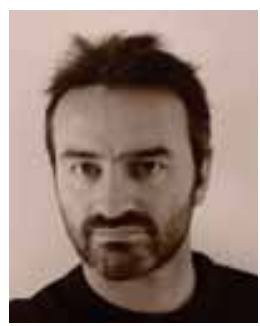

Jean-Stéphane Bailly Jean-Stéphane Bailly received the Engineer degree in agronomy, the M.S. degree in biostatistics, and the Ph.D. degree in hydrology from the University of Montpellier, France. He has been a member of the French Civil Corps of Water and Forestry Engineers since 1991. He is senior lecturer and scientist in physical geography at AgroParisTech, Montpellier, France. His research is devoted to spatial observations and parametrizations for hydrological modeling. http://www.researcherid.com/rid/C-2391-2011

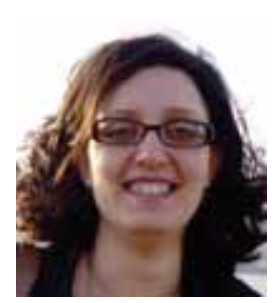

Nesrine Chehata Nesrine Chehata received the Diplom. Engn. in Physics from the Ecole Nationale Suprieure de Physique de Strasbourg, 2001 and the M.S degree in Image processing from the university of Strasbourg I, 2001. She defended her PhD Thesis in computer vision and image processing in 2005 at the university of Paris 5. She worked in collaboration with the IGN (French mapping Institute) in MATIS Lab and the CNES (French Space Agency). From 2006, she has been helding a teaching position as associate professor in the EGID institute at the university of Bordeaux which than became in 2011 the ENSEGID engineering school of Environnement, Geo-resources and sustainability). From 2012 to 2013, she was a research fellow at the IRD-UMR LISAH lab (French Institute of research for development) in Tunis, Tunisia. Her research interests are pattern recognition, machine learning and feature selection applied to remote sensing data such as airborne lidar data, hyperspectral images and VHR optical satellite images for environmental applications. She is member of the IEEE and the IEEE Remote Sensing Society.

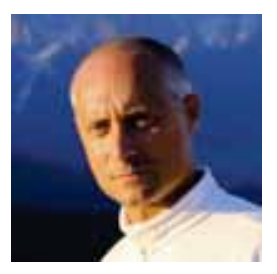

Paolo Tarolli Paolo Tarolli is Associate Professor at University of Padova (Italy). He has held Visiting Professor positions at several universities (e.g. China University of Geosciences in Beijing, National Cheng Kung University, EPFL). He is expert in digital terrain analysis, human-Earth interactions, Earth surface processes analysis through high-resolution topography, natural hazards, shallow landslides, hydro-geomorphology, geomorphic features extraction in alpine and floodplain context, anthropogenic feature extraction in anthropogenic landscapes, LiDAR and Structure from Motion applications, and GIS. In April 2015 he was nominated Science Officer of the European Geoscience Union (EGU) for the Natural Hazard Division (NH6: Remote Sensing \& Hazards). Tarolli is Editor of the journal Natural Hazards and Earth System Sciences and member of the Editorial Board of Land Degradation \& Development, Earth Surface Processes \& Landforms, Journal of Mountain Sciences, Anthropocene, and Heliyon. He is member of the American Geophysical Union, European Geoscience Union, British Society for Geomorphology, Asia Oceania Geosciences Society (AOGS). http://www.tesaf.unipd.it/en/paolo-tarolli http://orcid.org/0000-0003-0043-5226

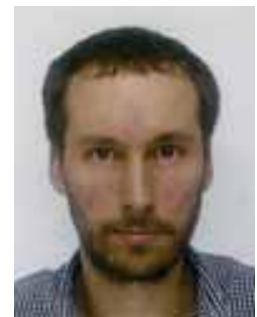

Florent Levavasseur Florent Levavasseur received the Engineer degree in agronomy, and the Ph.D. degree in hydrology from the University of Montpellier, France. He is scientist in agronomy at INRA, Thiverval-Grignon, France. His research is devoted to spatial modeling of cropping systems. 